\title{
Horizontal ridge augmentation using guided bone regeneration technique in two young patients with localized alveolar ridge defect: A case report
}

\author{
Do-Hyung Kim ${ }^{1}$ and Seong-Nyum Jeong ${ }^{1,2 *}$
}

${ }^{1}$ Department of Periodontology, Wonkwang University Daejeon Dental Hospital, Wonkwang University College of Dentistry, Daejeon, Republic of Korea ${ }^{2}$ Institute of Wonkwang Dental Research, Wonkwang University College of Dentistry, Iksan, Republic of Korea

Lateral ridge augmentation using guided bone regeneration technique is a frequently performed procedure that is used for restoring localized bone defects after extraction. In particular, demineralized bovine bone material and absorbable collagen membrane have been frequently used in adult patients before implant placement. However, the use of this procedure in adolescents before orthodontic tooth movement has rarely been reported. Herein, we present the cases of two young patients who underwent lateral ridge augmentation using the guided bone regeneration technique before implant placement and orthodontic tooth movement. Two patients in this case report showed successful clinical results with significant bone gain.

Key Words: Adolescent, Bone regeneration, Dental implants, Membranes, Orthodontics

(c) This is an open-access article distributed under the terms of the Creative Commons Attribution Non-Commercial License (http://creativecommons.org/licenses/by-nc/4.0) which permits unrestricted noncommercial use, distribution, and reproduction in any medium, provided the original work is properly cited.

\section{서 론}

발치 후 치조제의 수직, 수평적인 결손은 임상에서 흔하게 관 찰되는 현상으로, 치조제의 생리적 재형성의 결과로 인하여 나 타나게 된다[1,2]. 발치와의 생리적 재형성의 결과로 나타나는 치조제 결손은 주로 협측골의 소실로 나타나며, 발치 후 약 3개 월까지 급격히 나타나게 된다[1]. 이러한 치조골의 흡수는 주로 다발골로 이루어진 협측 및 순측 치조골에서 설, 구개측에 비해 더 크게 나타나서 추후 임플란트의 식립이나 교정적 치아이동 에 부정적인 영향을 미치게 된다[3,4].

발치 후 일어나는 치조제 결손을 극복하기 위한 방법으로 다 양한 골이식재와 차폐막을 이용한 골유도재생술(guided bone regeneration, GBR)이 수십 년간 성공적으로 사용되고 있다[5]. 과거에는 주로 자가골과 비흡수성 차폐막을 이용한 GBR이 표
준으로 여겨졌으나, 최근에는 이종골, 합성골 등 다양한 골대체 재와 흡수성 차폐막을 이용한 GBR도 널리 사용되고 있다[6]. 성 공적인 GBR을 통해 임플란트의 심미성 및 장기 예후를 개선할 수 있으며, 교정 전에 시행하여 공간 폐쇄 시 나타날 수 있는 치 은의 함입을 방지할 수 있음이 보고되었다 $[4,7,8]$.

$\mathrm{GBR}$ 을 시행 받는 환자들의 경우 대게 성인이며, 성장을 마치 지 않은 미성년 환자에게 이러한 술식을 진행한 증례는 일부 구 개열 환자 증례들을 제외하고는 흔히 보고되지 않고 있다. 본 증 례보고에서는 임플란트 식립을 위한 공간 회복 및 조기상실 치 아로 인한 공간 폐쇄를 위해 교정치료를 계획하고 있는 미성년 환자에게 GBR을 시행하여 성공적인 골 증대를 획득한 두 증례 를 소개하고자 한다.

상기 연구는 원광대학교 치과대학 대전치과병원 임상시험심 사위원회(Institutional Review Board)의 심의를 통과하였다

Received October 21, 2019; Revised November 26, 2019; Accepted November 26, 2019

${ }^{*}$ Corresponding author: Seong-Nyum Jeong, Department of Periodontology, Wonkwang University Daejeon Dental Hospital, Wonkwang University College of Dentistry, 77 Dunsan-ro, Seo-gu, Daejeon 35233, Republic of Korea.

Tel: +82-42-366-1141, Fax: +82-42-366-1115, E-mail: seongnyum@wku.ac.kr 
(IRB no. WKDIRB 20170906).

\section{증례보고}

\section{Case 1: 18세 남환에서 임플란트 식립 전 하악 좌측 전치 (\#31) 부위 guided bone regeneration 및 임플란트 식립}

18세 남환이 원광대학교 대전치과병원 교정과에서 하악 좌측 전치(\#31) 임플란트 식립을 주소로 치주과로 의뢰되었다. 환자 는 약 11년 전 \#31 치아를 유치로 착각하여 발치한 후 레진 스 플린트 상태로 내원하였고 임상 및 방사선 사진상에서 하악 전 치부의 총생 및 \#31 부위 Seibert's class III의 치조제를 확인할 수 있었다(Fig. 1) [9]. 환자는 \#31 부위 임플란트 식립을 동반한 교정 치료를 원하고 있었고, 수술적 치료에 영향을 미칠만한 전 신적 문제는 없었다. 치주과에서는 \#31 부위 GBR 후 단계적 임 플란트 식립을 계획하였다. 하악 우측 측절치(\#42) 협측 원심 선 각에서부터 열구 내 절개를 시작하여 무치악 융선 부위에는 치 조정 상방 수평 절개를 시행하였고, 하악 좌측 측절치(\#32) 원심 선각까지 열구 내 절개를 연장하였다. 판막의 양측 끝으로 수직 절개를 시행하였고, 하악 우측 전치(\#41)와 측절치(\#42) 치간유 두 보존을 위해 해당부위에는 치간유두보존 판막 거상을 시행 하였다(Fig. 2A). 판막 거상 후 위축된 치조제를 확인할 수 있었 고, 흡수성 차폐막(Lyoplant ${ }^{\circledR}$; B.Braun, Melsungen, Germany) 을 결손부 형태에 맞추어 재단하여 미리 적용하였다. 이후 결 손부의 순, 설측으로 탈단백우골이식재(demineralized bovine bone matrix, DBBM) (OCS-B ${ }^{\circledR}$; Nibec, Jincheon, South Ko$\mathrm{rea}$ )를 $0.5 \mathrm{~mL}$ 적용하고 흡수성 차폐막을 이식재 상방으로 덮 었다(Fig. 2B, C). 비흡수성 나일론 봉합사를 이용하여 수평 매 트리스 봉합 및 단순 단속 봉합을 시행하였고, 약 2주 후에 발사 를 시행하였다(Fig. 2D). 이후 6개월 추적관찰 시점까지 임상적 인 부작용 없이 잘 치유되었다(Fig. 3A). Cone beam computed tomography $(\mathrm{CBCT})$ 상의 치조제의 수평폭은 치조제의 근원심 의 중앙에서 치조정과 치조정 하방 $3 \mathrm{~mm}$ 에서 측정하여 평균값 으로 나타냈다. 방사선적으로 술 전 $1.79 \mathrm{~mm}$ 였던 치조제 폭이 $7.95 \mathrm{~mm}$ 까지 증가하여 $6.16 \mathrm{~mm}$ 의 방사선적 골증대를 보였다 (Fig. 3B, C, Table 1). 환자는 골증대 수술 이후에 1년 이상의 교 정치료를 통해 하악 전치부 총생을 해결하고 \#31 부위에 임플 란트를 식립할 수 있는 공간을 회복하였고, 환자의 연령이 20 세가 되어 악골 성장이 마무리되었다고 판단된 GBR 수술 후 1 년 7개월 시점에 직경 $3.0 \mathrm{~mm}$, 길이 $10.0 \mathrm{~mm}$ 임플란트 고정 체(Astratech ${ }^{\circledR}$; Dentsply Sirona, York, PA, USA)를 \#31부위에 식립하였다[10]. 식립 4개월 시점에서 2차 수술을 시행하였고 (Fig. 3D), 이후 추적관찰 시점까지 임플란트 임상적 부작용 없 이 유지되고 있다.

\section{Case 2: 12세 여환에서 교정적 치아이동 전 하악 좌측 제2 소구치(\#35) 부위의 guided bone regeneration}

12세 여환이 하악 좌측 제2 소구치(\#35)의 결손 및 돌출입을 주소로 본원 교정과에 내원하였다. 환자는 약 1 달 전 하악 좌측
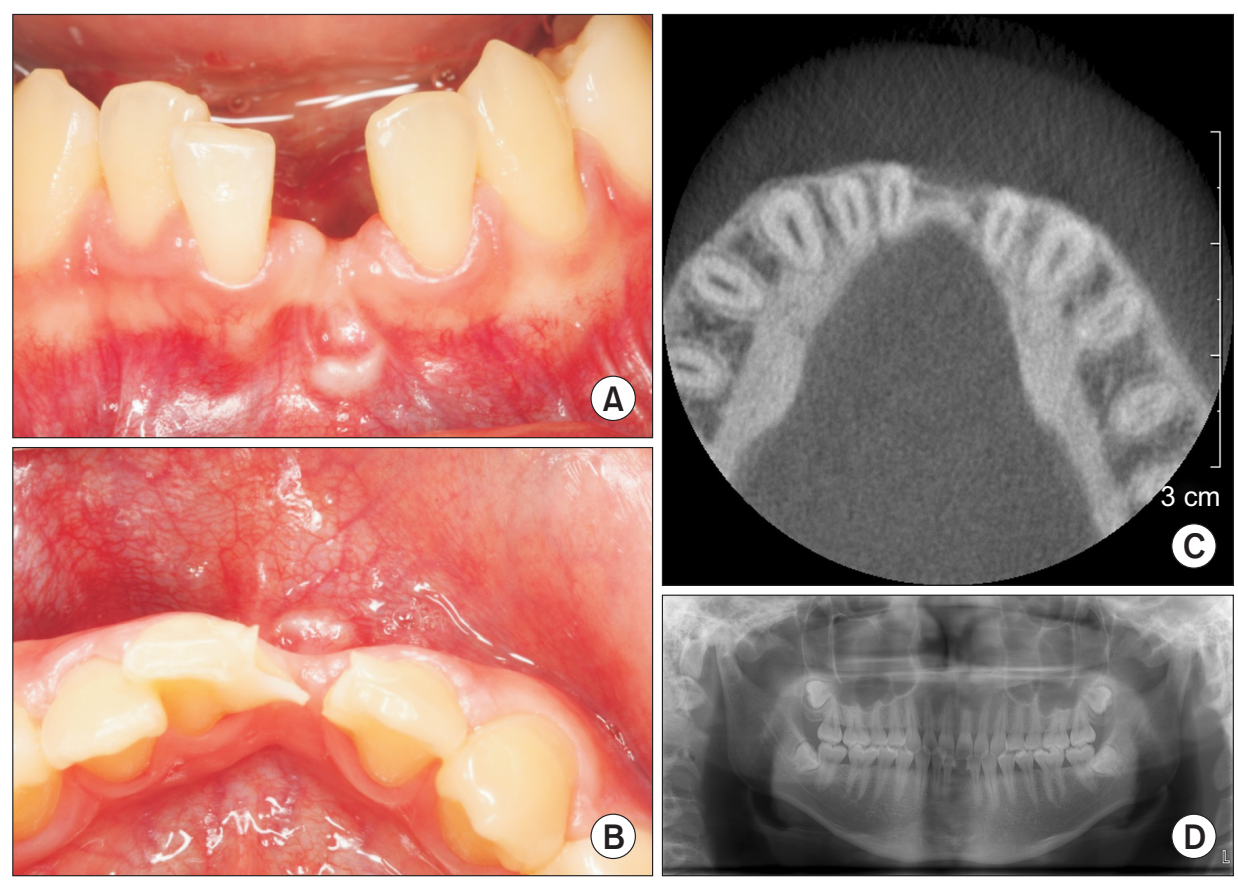

Fig. 1. Clinical and radiographic photograph before treatment of case 1 patient. (A, B) Seibert's class III ridge atrophy on \#31 site, (C) cone beam computed tomography image on axial view at \#31 site, (D) panoramic radiography of case 1 patient at first visit. 

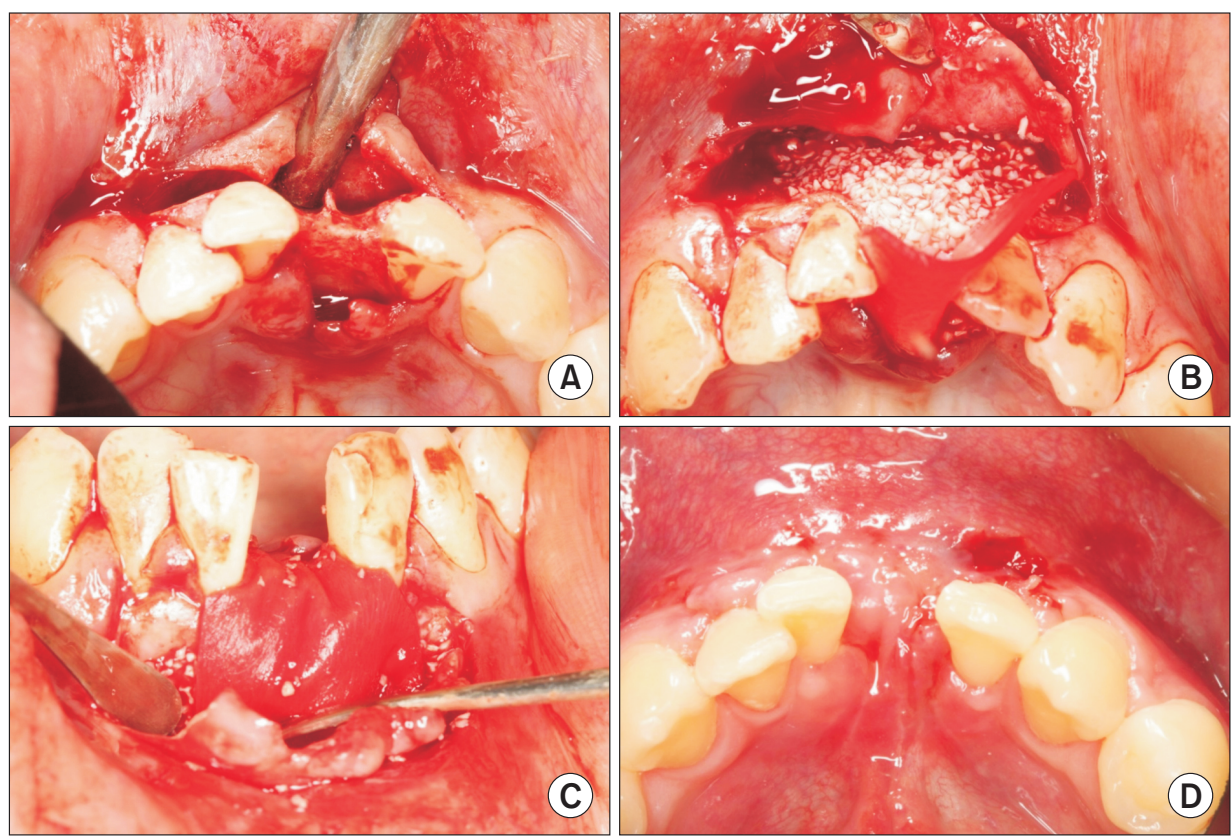

Fig. 2. Clinical photograph during and after surgical procedure of case 1 patient. (A) After incision and flap elevation, (B) bone graft application with the cut barrier membrane in the periosteum, (C) adaptation of the barrier membrane, (D) after 2 weeks stitch out.
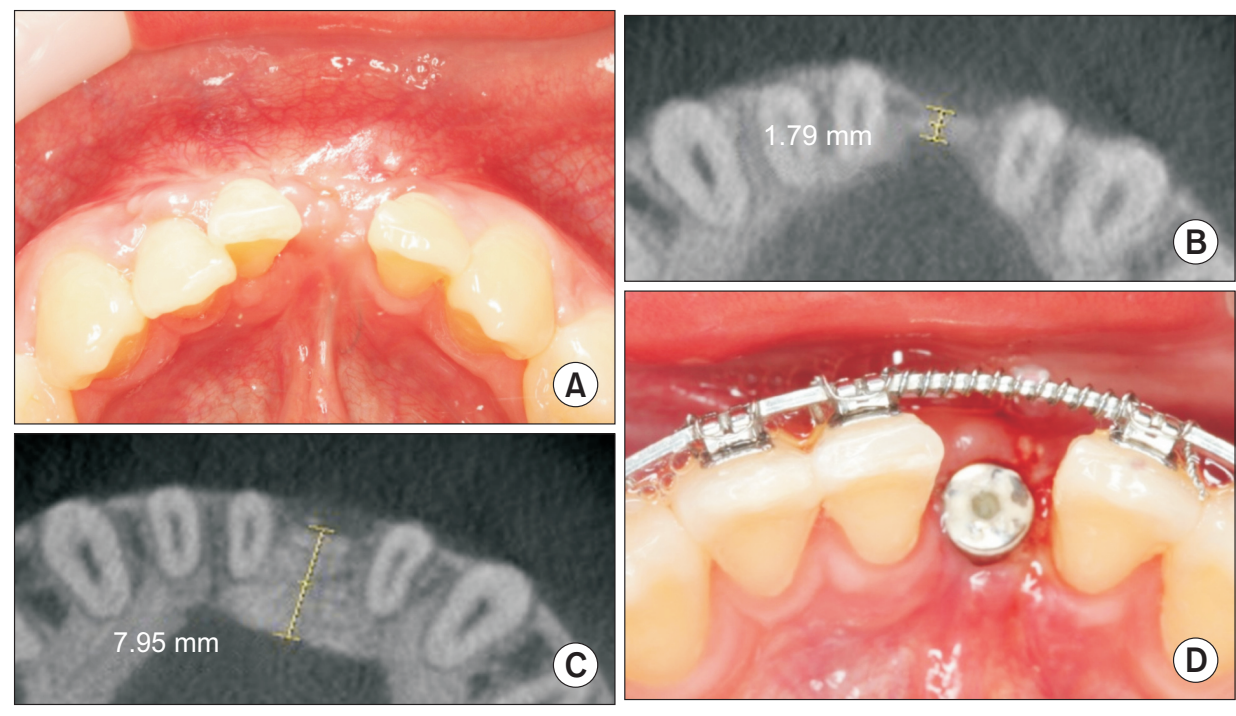

Fig. 3. Clinical photograph at 6 months after guided bone regeneration (GBR) of case 1 patient. (A) Augmented ridge on \#31 site, (B) alveolar bone width on cone beam computed tomography (CBCT) image before GBR procedure, $(\mathrm{C})$ alveolar bone width on CBCT image after GBR procedure, (D) clinical photograph after orthodontic treatment and implant placement after 7 months.

Table 1. Comparison of alveolar bone width of patients pre- and postoperatively

\begin{tabular}{cccc}
\hline Case & Preoperative & Postoperative & Bone gain \\
\hline 1 & $1.79 \mathrm{~mm}$ & $7.95 \mathrm{~mm}$ & $+6.16 \mathrm{~mm}$ \\
2 & $8.39 \mathrm{~mm}$ & $10.53 \mathrm{~mm}$ & $+2.14 \mathrm{~mm}$ \\
\hline
\end{tabular}

제2 유구치를 발거 하였으나, 선천적으로 하악 좌측 제2 소구치 가 결손된 상태였다. \#35 결손 부위의 치조제는 임상적, 방사선 적으로 수평적 위축을 보이고 있었다(Fig. 4). 교정과에서는 제 1 소구치의 후방 이동을 결정하였고, 위축이 심한 치조제 쪽으
로 치아 이동 시에 발생 가능한 치은 퇴축과 골 결손을 예방하기 위하여, 치아 이동 전에 수평 치조제의 폭 증대술을 시행해 줄 것을 치주과에 요구하였다[11]. 환자는 수술에 영향을 줄 전신 건강상의 문제는 보이고 있지 않아 치조제 결손부위에 $\mathrm{DBBM}$ $\left(\mathrm{OCS}^{\mathrm{B}}{ }^{\circledR}\right)$ 및 흡수성 차폐막(Osseoguard ${ }^{\circledR}$; Zimmer Biomet, Warsaw, IN, USA)을 이용한 GBR을 계획하였다. 하악 좌측 제1 소구치(\#34) 근심 선각에서부터 열구 내 절개를 시작하여 결손 부 치조제 상방 중앙부에 수평절개를 시행하였으며, 하악 좌측 제1 대구치(\#36) 근심선각까지 열구 내 절개를 연장하였다(Fig. $5 \mathrm{~A}$ ). 판막 거상 후 흡수성 차폐막을 결손부 형태에 맞추어 재단 

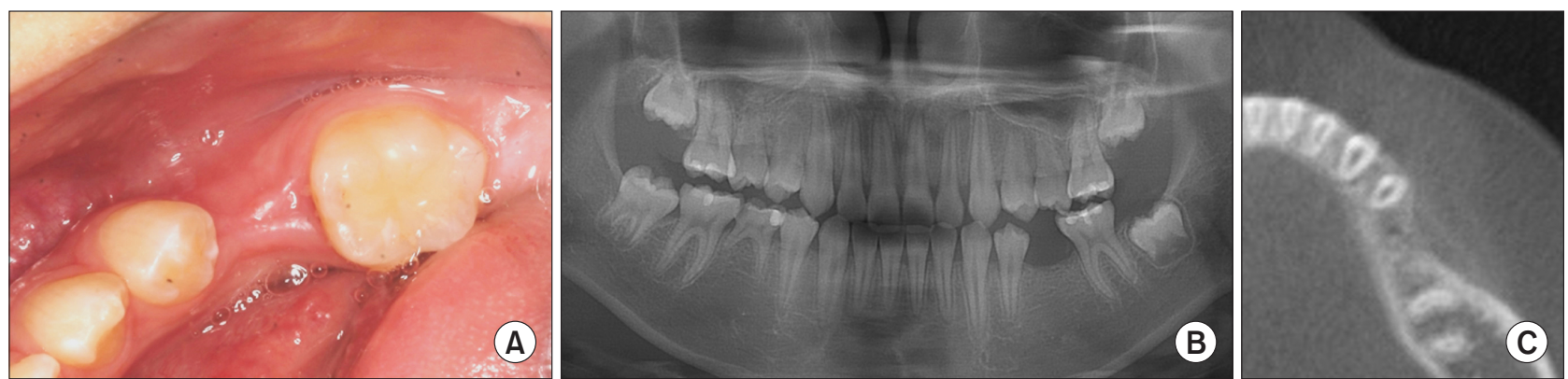

Fig. 4. Clinical and radiographic photograph before treatment of case 2 patient. (A) Buccal and lingual ridge atrophy, (B) panoramic radiograph, (C) cone beam computed tomography image on axial view at \#35 site.
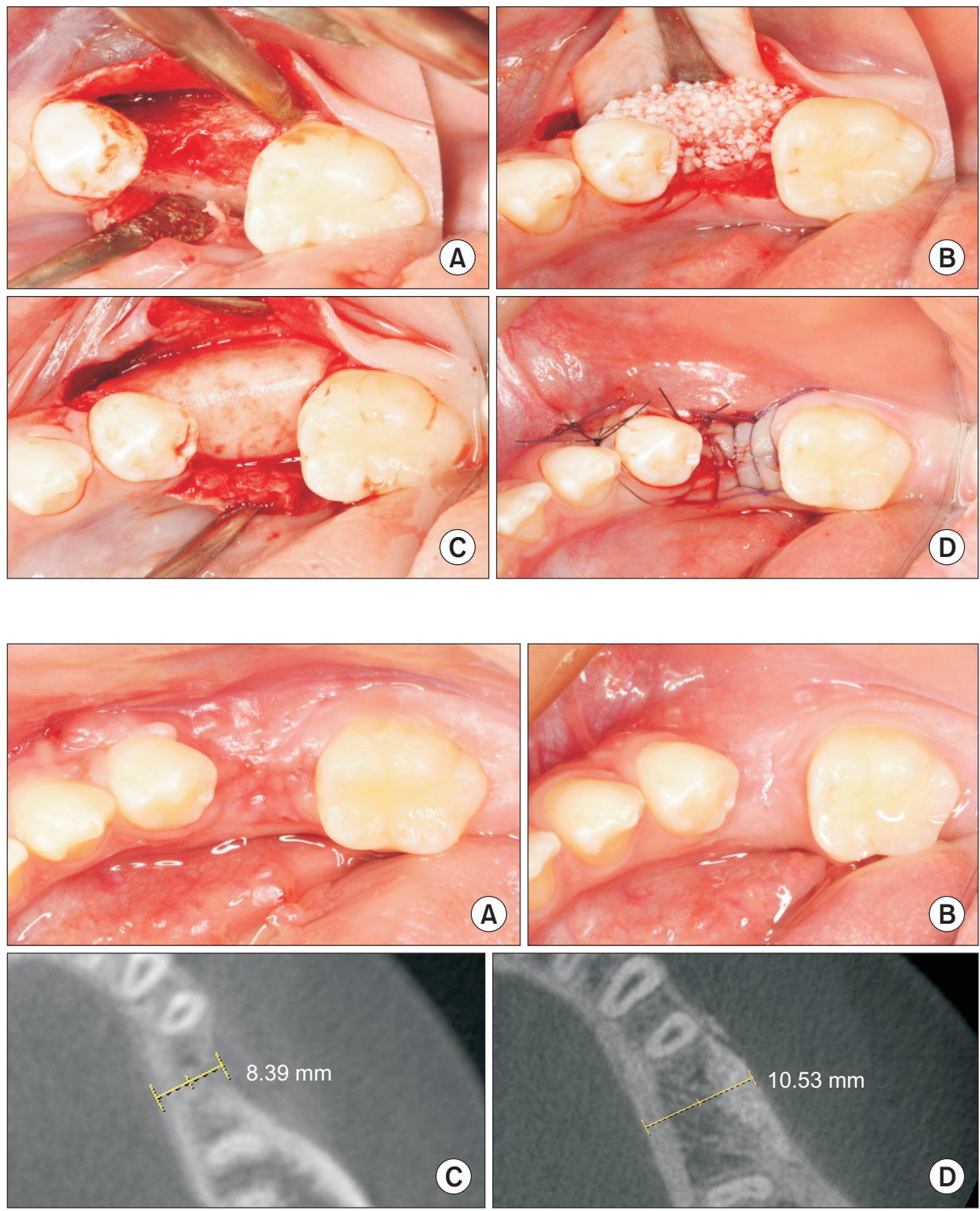

Fig. 5. Clinical photograph during and after surgical procedure of case 2 patient. (A) After incision and flap elevation, (B) bone graft material and membrane application, (C) barrier membrane covering bone graft material, (D) after suturing.

Fig. 6. Clinical Photograph after guided bone regeneration surgery and comparison of bone width on cone beam computed tomography (CBCT) image. (A) After 2 weeks stitch out, (B) after 8 months follow up, (C) CBCT axial view before surgery, (D) CBCT axial view after 8 months surgery. Augmented bone is observed. 
하였고 DBBM을 적용하였다(Fig. 5B). 이후 재단한 차폐막을 이 식재 상방에 덮고 흡수성 봉합사를 이용한 수평 매트리스 봉합 및 비흡수성 나일론 봉합사를 이용한 단순단속봉합을 시행하였 다(Fig. 5 C, D). 수술 후 2주 시점에서 봉합사는 제거되었고 6달 시점까지 임상적인 부작용 없이 좋은 치유를 보였다(Fig. 6A, B). $\mathrm{CBCT}$ 상의 치조제 수평폭은 치조제의 근원심의 중앙에서 치조 정과 치조정 하방 $3 \mathrm{~mm}$ 에서 측정하여 평균값으로 나타냈다. 술 전 방사선적으로 $8.39 \mathrm{~mm}$ 의 폭을 보였던 치조제는 수술 후 8 개 월 시점에서 $10.53 \mathrm{~mm}$ 의 치조제 폭을 보여 $2.14 \mathrm{~mm}$ 의 수평적 증대를 보였다(Fig. 6C, D, Table 1). 이후 환자는 다른 치과에서 교정 치료를 받고 있다.

\section{고 찰}

본 증례보고에서는 미성년 환자에서 DBBM과 흡수성 차폐막 을 이용한 $\mathrm{GBR}$ 을 통해 성공적으로 수평 치조제의 증대를 얻은 두 증례를 소개하였다. 두 증례 모두 조기에 영구치를 상실하거 나 영구치가 선천적으로 결손된 미성년 환자가 대상이었으며, 증례 1 의 환자는 임플란트의 식립을 위해, 증례 2 의 환자는 교 정적 치아 이동을 위해 수평적 치조제 증대가 필요한 상황이었 다. 따라서 환자들의 나이가 어림에도 불구하고 수술적 처치를 시행하였다.

발치 혹은 치아의 선천적 결손은 치조제의 생리적 재형성 과 정을 초래하게 된다. 특히 환자 2에서와 같이 선천적으로 영구 치가 존재하지 않을 확률은 $0.15 \%$ 에서 $16.2 \%$ 에 달한다고 보고 되고 있으며, 특히 하악 제2 소구치와 상악 측절치가 주로 영향 을 받는 것으로 보고되고 있다[12,13]. 이러한 치아의 결손은 전 반적인 치조제 부피의 감소를 초래하게 되며, 일반적으로 수평 적 치조제 폭의 감소가 더 급격하게 일어난다. 체계적 문헌 고 찰 연구에 의하면 수평적 폭의 감소는 평균 $3.87 \mathrm{~mm}$ 에 달하며, 수직적 높이의 감소는 평균 $1.53 \mathrm{~mm}$ 로 상대적으로 적게 나타 난다[1]. 수평적 치조제 폭의 감소는 Seibert's classification상 class 1에 해당하는 치조제의 결손을 초래하게 된다[9].

Seibert's class 1 치조제 결손을 극복하기 위한 방법으로 $\mathrm{GBR}$ 을 통한 측방 치조제 증대술을 시행하게 된다. 과거에는 자 가골과 비흡수성 차폐막이 주로 사용되었으나 자가골 채취의 어려움 및 자가골의 흡수가 단점으로 부각되어 최근에는 DBBM 과 흡수성 차폐막이 주로 이용되고 있다[14]. DBBM의 경우 가 장 많은 연구가 이뤄진 골 대체재로, 임플란트 주위에 골 이식 을 시행하는 상황에서 표준으로 간주되고 있다 $[5,15]$. 콜라겐 을 주 성분으로 하는 흡수성 차폐막은 흡수 과정에서 조직의 이 물반응을 일으키지 않고 추가적인 제거 수술이 필요하지 않은 장점을 보인다[5]. DBBM과 흡수성 콜라겐 차폐막을 이용하여
Seibert's class 1 치조제에 GBR을 시행한 선행 연구에서 180일 후 $1.4 \mathrm{~mm}$ 가량의 유의한 수평 치조제 증대를 얻은 결과를 보고 하였으며[16], 본 연구에서도 치조제 폭의 증가를 관찰할 수 있 었다.

이러한 측방 치조제 이식을 통한 임플란트의 식립은 $93.75 \%$ 에서 $100 \%$ 에 달하는 생존율이 보고되고 있으며, 성공률의 측면 에서도 다수의 연구에서 $90 \%$ 이상을 보고하고 있다[7,14]. 특히 $\mathrm{GBR}$ 과 동시에 임플란트를 식립하는 것은 임플란트에 생존율 및 성공률에 크게 영향을 미치지 않는다는 보고가 있는 것을 볼 때 GBR을 동반한 임플란트의 식립은 예지성 있는 치료방안으 로 간주될 수 있다[17].

교정적 치아 이동을 앞두고 이뤼지는 GBR의 경우 치아 이동 시에 일어날 수 있는 추가적인 골 소실을 막거나 교정적 공간 폐 쇄 시 나타날 수 있는 치은의 함입을 막기 위해 고려될 수 있다 [3,8]. 성인을 대상으로 발치 2달 후 GBR을 시행하고 술 후 2.5 개월 시점에서 해당부위로 치아를 이동시킨 증례보고에서 성공 적인 임상적 결과를 보고하였다[3], 본 증례보고의 증례 2 환자 와 유사한 연령대를 보이는 11-13세 연령의 소아 대상으로 한 증례보고에서도 성공적인 치아이동과 치은 함입의 방지를 보 여, 교정 전에 시행되는 $\mathrm{GBR}$ 이 연령과 크게 관계없이 성공적인 결과를 보일 수 있음을 확인할 수 있었다[8].

교정 전 $\mathrm{GBR}$ 을 시행해야만 하는 특징적인 골 너비가 현재 정 의되어 있지는 않으나, 증례 1 의 환자에서 치조정의 골 폭이 3 $\mathrm{mm}$ 이하로 좁았기 때문에 교정적 치아 이동 전에 GBR을 시행 하는 것은 예후에 도움이 될 것으로 생각된다. 또한 소아 환자에 게 교정적 치아 이동 및 Cleft 수술을 위해 GBR을 성공적으로 시행한 증례들이 보고되고 있으나, GBR 시 성인과의 차이점 등 에 대한 연구는 아직 부족한 실정이다. 만 17세까지 악골의 성 장이 지속되는 것을 감안할 때 조심스러운 접근이 필요할 것으 로 생각된다[3,8,10,18]. 연조직 또한 미성숙 상태이므로 절개 및 판막 조작 시 외상을 최소로 하여 예기치 않은 수술 후의 출 혈과 부종 및 치은 퇴축을 예방해야 할 것으로 보인다.

본 증례 발표에서 확인한 바와 같이, DBBM과 흡수성 차폐막 을 이용한 $\mathrm{GBR}$ 은 미성년자에서도 성공적으로 치조골을 재생할 수 있을 것으로 보이며, 치조골 재생 후 임플란트 식립이나 교정 적 치아 이동도 문제없이 진행되었지만, 본 증례의 결과는 매우 조심스럽게 해석되어야 한다. 연조직과 경조직의 성장이 진행 중에 있는 미성년자에게 GBR은 매우 제한적으로 시행되어야 하며, 추후 더 큰 집단을 대상으로 한 장기적 연구와, 대조군을 설정한 연구, 성인과의 결과 차이점 연구 등이 더 필요할 것으로 생각된다. 


\section{ACKNOWLEDGEMENTS}

This research was supported by Wonkwang University in 2019.

\section{CONFLICTS OF INTEREST}

The authors declare that they have no competing interests.

\section{ORCID}

\author{
Do-Hyung Kim \\ https://orcid.org/0000-0001-7846-6175 \\ Seong-Nyum Jeong \\ https://orcid.org/0000-0003-4890-989X
}

\section{REFERENCES}

1. Van der Weijden F, Dell'Acqua F, Slot DE. Alveolar bone dimensional changes of post-extraction sockets in humans: a systematic review. J Clin Periodontol 2009;36:1048-1058. doi: 10.1111/j.1600-051X.2009.01482.x.

2. Araújo MG, Lindhe J. Dimensional ridge alterations following tooth extraction. An experimental study in the dog. J Clin Periodontol 2005;32:212-218. doi: 10.1111/j.1600051X.2005.00642.x.

3. Carvalho RS, Nelson D, Kelderman H, Wise R. Guided bone regeneration to repair an osseous defect. Am J Orthod Dentofacial Orthop 2003;123:455-467. doi: 10.1067/ mod.2003.59.

4. Khojasteh A, Kheiri L, Motamedian SR, Khoshkam V. Guided bone regeneration for the reconstruction of alveolar bone defects. Ann Maxillofac Surg 2017;7:263-277. doi: 10.4103/ams.ams_76_17.

5. Benic GI, Hämmerle CH. Horizontal bone augmentation by means of guided bone regeneration. Periodontol 2000 2014;66:13-40. doi: 10.1111/prd.12039.

6. Zitzmann NU, Naef R, Schärer P. Resorbable versus nonresorbable membranes in combination with Bio-Oss for guided bone regeneration. Int J Oral Maxillofac Implants 1997;12:844-852.

7. Clementini M, Morlupi A, Canullo L, Agrestini C, Barlattani A. Success rate of dental implants inserted in horizontal and vertical guided bone regenerated areas: a systematic review. Int J Oral Maxillofac Surg 2012;41:847-852. doi: 10.1016/j.ijom.2012.03.016.

8. Reichert C, Wenghöfer M, Götz W, Jäger A. Pilot study on orthodontic space closure after guided bone regeneration. J Orofac Orthop 2011;72:45-50. German. doi: 10.1007/ s00056-010-0006-z.

9. Seibert JS. Reconstruction of deformed, partially edentulous ridges, using full thickness onlay grafts. Part I. Technique and wound healing. Compend Contin Educ Dent 1983;4:437-453.

10. Edwards CB, Marshall SD, Qian F, Southard KA, Franciscus RG, Southard TE. Longitudinal study of facial skeletal growth completion in 3 dimensions. Am J Orthod Dentofacial Orthop 2007;132:762-768. doi: 10.1016/ j.ajodo.2006.01.038.

11. Jati AS, Furquim LZ, Consolaro A. Gingival recession: its causes and types, and the importance of orthodontic treatment. Dental Press J Orthod 2016;21:18-29. doi: 10.1590/2177-6709.21.3.018-029.oin.

12. Rakhshan V. Congenitally missing teeth (hypodontia): a review of the literature concerning the etiology, prevalence, risk factors, patterns and treatment. Dent Res J (Isfahan) 2015;12:1-13.

13. Al-Ani AH, Antoun JS, Thomson WM, Merriman TR, Farella M. Hypodontia: an update on its etiology, classification, and clinical management. Biomed Res Int 2017;2017:9378325. doi: 10.1155/2017/9378325.

14. Aludden HC, Mordenfeld A, Hallman M, Dahlin C, Jensen T. Lateral ridge augmentation with Bio-Oss alone or Bio-Oss mixed with particulate autogenous bone graft: a systematic review. Int J Oral Maxillofac Surg 2017;46:1030-1038. doi: 10.1016/j.ijom.2017.03.008.

15. Jensen SS, Terheyden H. Bone augmentation procedures in localized defects in the alveolar ridge: clinical results with different bone grafts and bone-substitute materials. Int J Oral Maxillofac Implants 2009;24 Suppl:218-236.

16. Saravanan P, Ramakrishnan T, Ambalavanan N, Emmadi P, John TL. Efficacy of guided bone regeneration using composite bone graft and resorbable collagen membrane in Seibert's Class I ridge defects: radiological evaluation. J Oral Implantol 2013;39:455-462. doi: 10.1563/AAID-JOID-10-00211.

17. Bazrafshan N, Darby I. Retrospective success and survival rates of dental implants placed with simultaneous bone augmentation in partially edentulous patients. Clin Oral Implants Res 2014;25:768-773. doi: 10.1111/clr.12185.

18. Kawata T, Yuki M, Miyamoto Y, Fujita T, Kaku M, Kohno S, Tsutsui K, Ohtani J, Tenjo K, Motokawa M, Shigekawa M, Tohma Y, Kamada H, Tanne K. Guided bone regeneration to repair an alveolar bone defect in a girl whose cleft lip and palate had been repaired. Br J Oral Maxillofac Surg 2005;43:420-422. doi: 10.1016/j.bjoms.2004.11.008. 